\title{
Effect of Sulfonated-Melamine Formaldehyde as Superplasticizer in Cementitious Systems
}

\author{
SKM. Pothinathan ${ }^{1, a^{*}}$, J. Millar ${ }^{2, b}$, S. Christopher Gnanaraj $j^{3, c}$ \\ ${ }^{1}$ Department of Civil Engineering, Kalasalingam Academy of Research and Education, \\ Krishnankoil-626126, Tamilnadu, India \\ 2 Student, Mater of Technology, Department of Civil Engineering, Kalasalingam Academy of \\ Research and Education, Krishnankoil - 626126, Tamilnadu, India \\ ${ }^{3}$ Department of Civil Engineering, Kalasalingam Academy of Research and Education, \\ Krishnankoil-626126, Tamilnadu, India \\ a*s.k.m.pothinathan@klu.ac.in, bdavidmillar5554@gmail.com, cs.christophergnanaraj@klu.ac.in
}

Keywords: Sulfonated-Melamine Formaldehyde, Concrete, Superplasticizer, Fresh Concrete Properties, Mechanical Strength

\begin{abstract}
This paper studied the effect of Sulfonated-Melamine Formaldehyde (SMF) on the water cement ratio, setting time, compressive strength at various ages and an acid resistance test was conducted using sulfuric acid. Sulfonated-Melamine Formaldehyde is classified as superplasticizer. SMF was mixed with concrete at $1 \%-5 \%$ in volume fraction. But not much investigation was made. In this study it was found that the Sulfonated-Melamine Formaldehyde incorporated concrete mixture performing well in strength property and have more resistance to aggressive environment when compared to conventional concrete.
\end{abstract}

\section{Introduction}

In concrete ingredient, water cement ratio plays a vital role in enhancing properties like workability, strength, and durability. Higher water cement ratio gives good workability but leads to segregation of concrete ingredients and not consumed water during hydration process results in pores and cracks that affects the concrete strength and durability. Lower water concrete proportion prompts to higher strength and durability but make the mixture difficult to achieve uniform mix and may not flow well to compact and place the concrete. These problems can be resolve with water reducing admixtures. The water reducing admixtures are available in synthetic, organic, and water-soluble products. This water reducers are further classified into four groups Polynaphthalene sulfonates (PNS), Polymelamine sulfonates (PMS), Vinyl copolymers (VC) and Polycarboxylic ethers (PCE) [1]. In this the effect of PNS, PMS, VC is based on electrostatic repulsion and PCE is on steric hindrance effect [2].

Ibragimov [3] studied the early strength, and durability properties of concrete using four different superplasticizers namely naphthalenesulfonate and organic accelerator, polyoxyethylene derivatives of polymethacrylic acid, polyether carboxylates, and polyoxyethylene derivatives. He concluded that the naphthalenesulfonate and organic accelerator performed well in all aspect comparing other superplasticizers. Naphthalenesulfonate and organic accelerator gave improved strength in compression by 14-21 percentage, flexural strength by 54 percentage. The water absorption and shrinkage reduced by $45-54$ percentage and 53 percentage. Nakajima [8] studied the mechanism of calcium sulphate in cement with Polynaphthalene sulfonates. The results indicate the concentration of calcium sulphates result in flow loss of cement paste. He concluded

(c) (1) Content from this work may be used under the terms of the Creative Commons Attribution 3.0 license. Any further distribution of this work must maintain attribution to the author(s) and the title of the work, journal citation and DOI. Published under license by Materials Research Forum LLC. 
that the increased polynaphthalene sulfonates content results in decreased calcium sulphates absorption. This causes the less flow loss.

Cheah [4] examined the polycarboxylate-based superplasticizer in the properties of high-performance concrete. He used methoxy polyethylene glycols and isoprenyl polyethylene glycols as admixture. He also studied performance of blending both polycarboxylate. The result shows that the blended superplasticizer provides reduction in mechanical strength because of both foil and fibril like C-S-H gel co-formation the pores increases. He concludes that by comparing all admixed concrete methoxy polyethylene glycols shows slightly improved early compressive strength. Nowak-Michta [5] studied the impact in strength performance of air-entraining and superplasticizing admixed concrete. He used polycarboxylate-based superplasticizer for liquefaction. He concluded that the air entraining agent alone reduced the compressive strength. But the addition of air entraining admixture along with superplasticizer content by 1 to 13 percentage increases the strength performance of concrete.

Gupta [6] used superplasticizer in two types of concrete mix. One is 100 percent GGBS and other one is 50 percent GGBS and 50 percent fly ash admixed geopolymer concrete. He utilized various percentage of Glenium Sky 8630 a polycarboxylic based superplasticizer in his work. He noticed improvement in strength in all dosage of superplasticizer from 1 percentage to 3 percentage. The maximum strength development was noted with 3 percentage polycarboxylic based superplasticizer dosage in both types of mixtures. The superplasticizing effect was studied by Pei et al $[12,20]$ using sodium sulfanilate-phenol-formaldehyde (SSPF) and soluble acetoneformaldehyde, Mahmoud et al [16] used sulfonated acetophenone-formaldehyde resin and Chen et al [19] used sulphonated phenolic resin. All authors infer improved performance in their SPs.

From the above literatures it clearly signifies that the addition of superplasticizers in all mixtures like OPC, PPC, GGBS with calcium sulphate, fluoride and fly ash decreases the water binder ratio and increase the strength and durability. But there is very less investigation was conducted using Sulfonated-Melamine Formaldehyde as superplasticizer. A study was conducted by Lahallh [9] about the Sulfonated Melamine-Formaldehyde (SMF) as superplasticizer in the concrete on 1988 and concluded that the lab produced SMF performed well in all aspect than the industrial purchased Sulfonated Melamine-Formaldehyde. Arosio [10] used Sulfonated Melamine-Formaldehyde to produce building blocks. Other than these two studies no noticeable investigation was conducted using Sulfonated Melamine-Formaldehyde in cementitious system. The main purpose of the paper is to study the effect of Sulfonated Melamine-Formaldehyde as superplasticizer in concrete.

\section{Experimental study}

Concrete Materials

Ordinary Portland cement with 43 grades satisfying IS 8112 requirements was used in this study. The chemical composition and properties of OPC is shown in Table 1. The specific gravity of cement is $3.2 \mathrm{~g} / \mathrm{cm}$ 3and Zone I natural river sand were used throughout the study for mortar mix as per IS 383. The specific gravity of fine aggregate is 2.57 and the fineness modulus of 3.353 . Crushed stone from quarry as coarse aggregate having a specific gravity of 2.72 and maximum size of $20 \mathrm{~mm}$ used with specific grading as coarse aggregate. 
Table 1. Chemical substance and properties of Ordinator Portland cement

\begin{tabular}{|c|c|c|c|c|c|c|c|}
\hline \multicolumn{6}{|c|}{ Chemical Composition (\%) } & \multirow[t]{2}{*}{ Density } & \multirow{2}{*}{$\begin{array}{l}\text { Specific } \\
\text { area }\end{array}$} \\
\hline $\mathrm{SiO}_{2}$ & $\mathrm{CaO}$ & $\mathrm{Al}_{2} \mathrm{O}_{3}$ & $\mathrm{Fe}_{2} \mathrm{O}_{3}$ & $\mathrm{MgO}$ & Loss on ignition & & \\
\hline 76 & .53 & 5.89 & 3.40 & 1.45 & 1.14 & $\mathrm{~g} / \mathrm{cm}$ & \\
\hline
\end{tabular}

\section{Sulfonated Melamine-Formaldehyde}

Industrial available Sulfonated Melamine-Formaldehyde was obtained in liquid form with $20 \%$ solid content. It a colorless liquid having specific gravity of 1.1 and viscosity of $5 \mathrm{mPa}$.s. The $\mathrm{pH}$ value of Sulfonated Melamine-Formaldehyde liquid is 8 .

\section{Mixing, casting, and curing}

The concrete blend composition was according to IS 10262 . The cement content was $310 \mathrm{~kg} / \mathrm{m}^{3}$. The water content of the conventional concrete and SMF admixed concrete was adjusted to obtain the slump value $80 \mathrm{~mm}$ [11]. In a rotating drum the concrete ingredients are added. Water and Sulfonated Melamine-Formaldehyde mixed and added to the concrete mixture. After the uniform mixing the concrete mix was cased and kept in room temperature for 24 hours. All specimens are demolded and cured in water until test date.

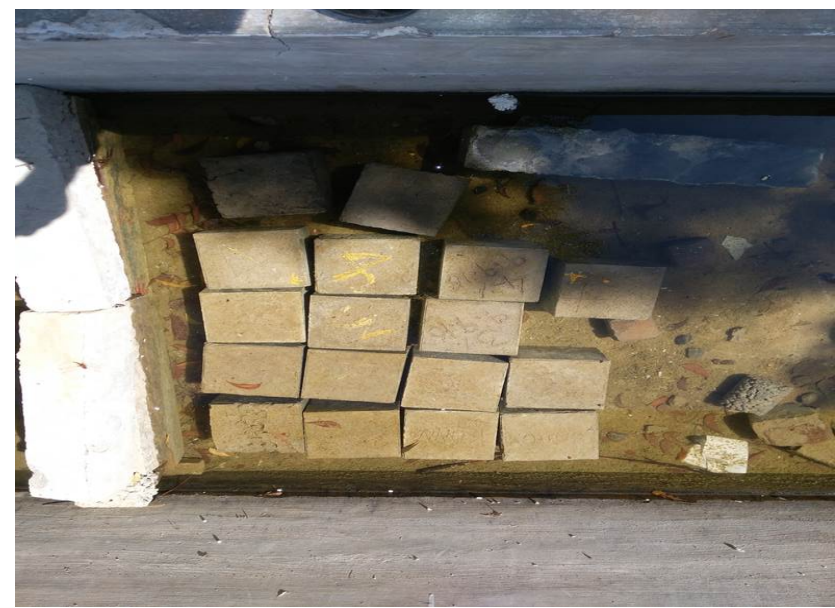

Fig. 1.Curing of Specimen

\section{Testing}

Setting time test was conducted confirming to IS 4031 using Vicat's needle apparatus. The time elapsed to fail to pierce the specimen $5.0 \mathrm{~mm}$ measure from the bottom was noted.

Compressive strength of concrete cubes of size $15 \times 15 \times 15 \mathrm{~cm}$ were used according to IS516 and tension strength was conducted in cylindrical specimen with $300 \mathrm{~mm}$ long and $150 \mathrm{~mm}$ diameter according to IS5816. Flexural strength test was conducted by using $15 \times 15 \times 70 \mathrm{~cm}$ prism according to IS 516. The age of compression test were 3 days, 7 days, 14days and 28 days. The ages of split tensile and flexural test were 4 weeks. Average of three specimen was used in each strength test.

Acid resistance test was conducted in cube specimen. After 28days of water curing the specimens were taken out and kept dry in room temperature for $24 \mathrm{hrs}$. Then the specimens were submerged in water with $5 \%$ sulfuric acid by weight for 90 days. After that the specimens were washed and dried for $24 \mathrm{hrs}$ before testing. 


\section{Test results and discussion:}

Effect on fresh concrete

The effect of Sulfonated Melamine-Formaldehyde as superplasticizers with different dosage level in concrete mixture on water content to attain $80 \mathrm{~mm}$ slump value was examined. Fig.2. shows the unit water reduction due to the effect of Sulfonated Melamine-Formaldehyde. Sulfonated Melamine-Formaldehyde act as superplasticizer and considerably reduce the water content proportionally. The resin content increases the water content decease simultaneously. 5 percentage increase in SMF content reduced water up-to 30 percentage. The resin neutralizing the surface resistance of the cement grains and reducing the viscosity. This results the rapid scattering of cement particles and workability of the mixture was increasing with decreased water content.

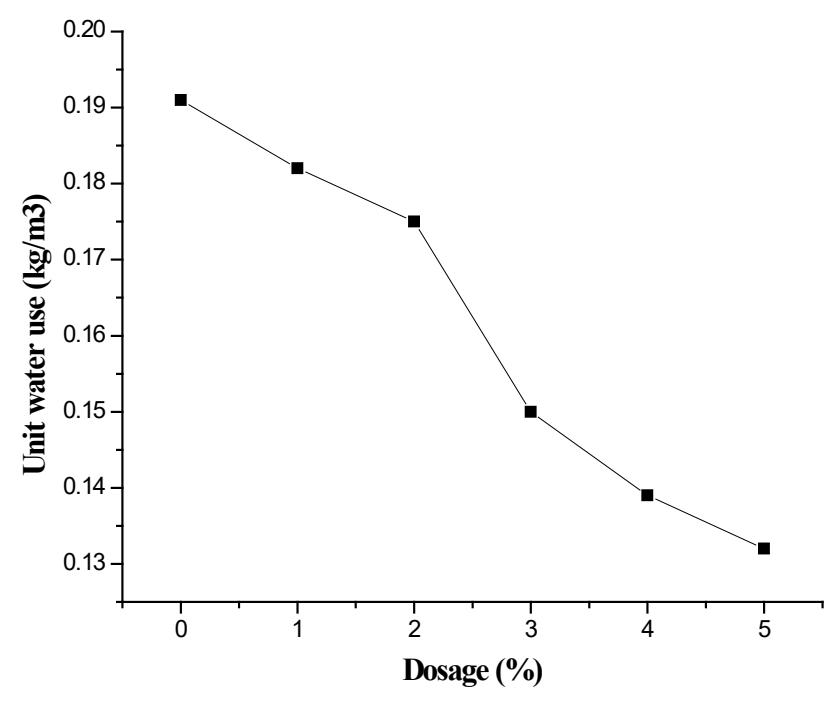

Fig. 2. Unit water reduction on concrete mixture

Fig.3. displays the impact on Sulfonated Melamine-Formaldehyde in initial setting time on concrete mixture comparing to conventional concrete. The test was conducted in Vicat's needle apparatus and the penetration resistance by the needle versus time was noted for different SMF dosage levels. The SMF dispersed the cement particle to increase the flowability and affects the hydration processes of cement. Because of this the initial setting time of cement delayed. This retardation effect is increasing by increasing Sulfonated Melamine-Formaldehyde 


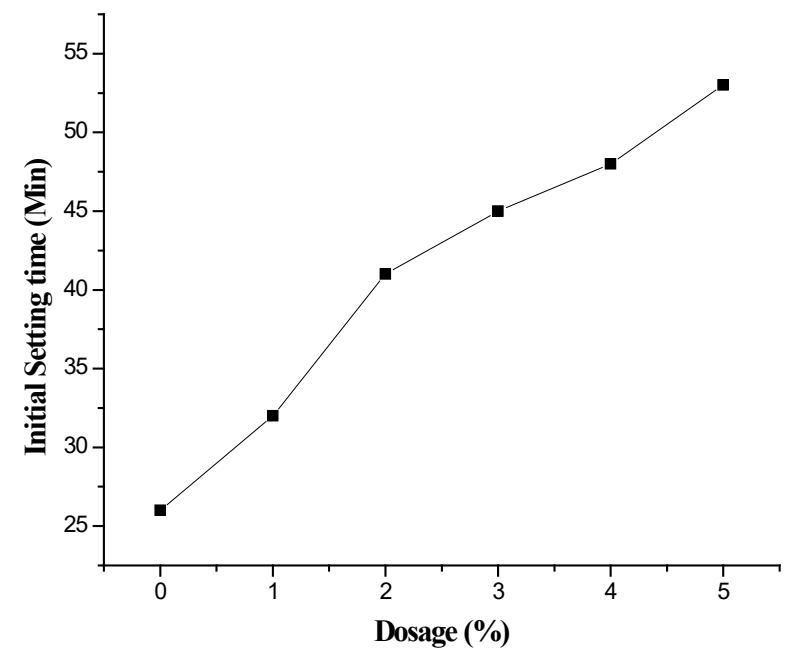

Fig. 3. Initial setting time of concrete mixture

Effect on harden concrete property

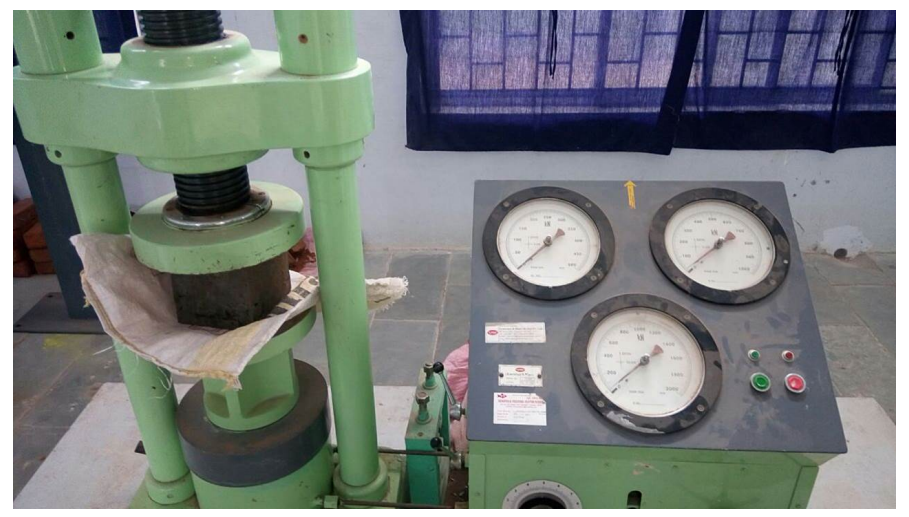

Fig. 4. Cube testing

Fig 5. Shows the compression strength of concrete with different dosages $(1 \%-5 \%)$ of Sulfonated-Melamine Formaldehyde at different ages (3days, 7days, 14days and 28days). The SMF incorporated concrete mixture provided higher compression strength than the conventional concrete at all dosages and all tested ages. 5 percentage admixed concrete mixture signifies rise in compression strength when compared with smaller dosages. This strength rise is because of the reduction in water content of fresh concrete mixture. It is a chain reaction that the reduction in water content leads to reduction pores content. So higher dense concrete can be produced with higher workability using high range water reducers. SMF also did the same to the concrete mixture by elevating the compressive strength. But dosage of 3 percentage of Sulfonated-Melamine Formaldehyde represent optimum strength rise. There is strength rise after 3 percentage dosage, but the result indicates no drastic change. As the economic concern, it is advisable to use 3 percentage admixture in the concrete mixture. 


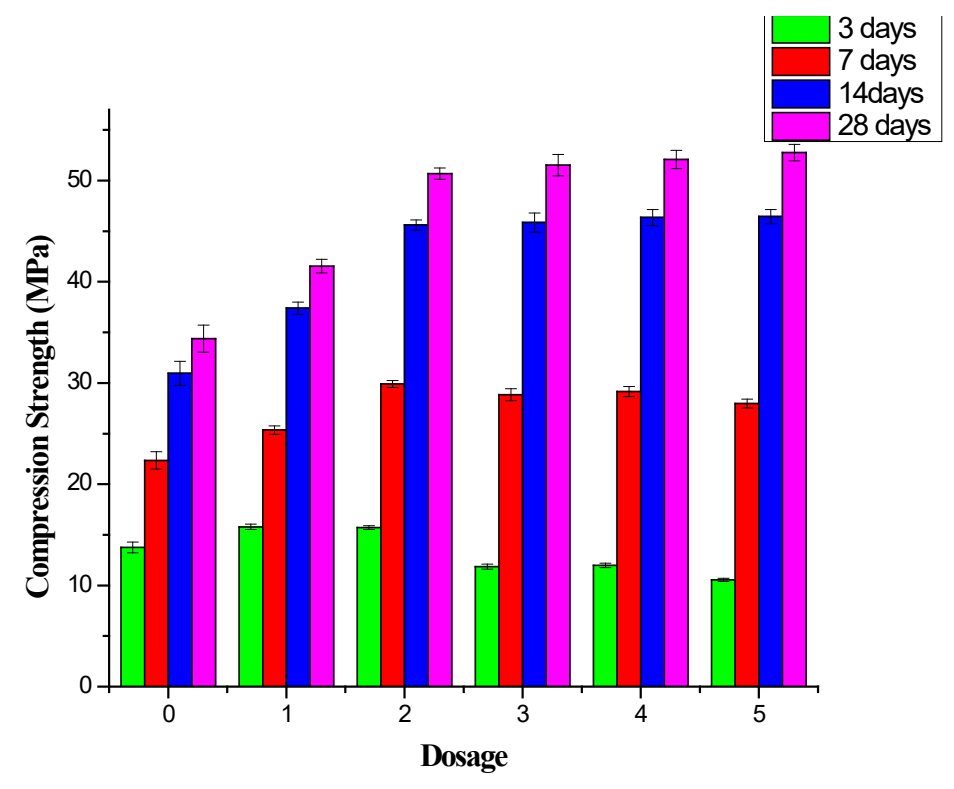

Fig. 5. Compression strength of concrete mixture

Fig 6. Shows the split tensile strength of conventional and SMF admixed concrete after 28days of aging. Tensile strength was improved by increasing the SMF dosage level. It is ostensible that the tensile strength of admixed concrete is higher than the conventional concrete. Due to the water reduction this strength hike is achievable. As discussed in the compression property the 3-percentage dosage of SMF is optimum in tensile strength also.

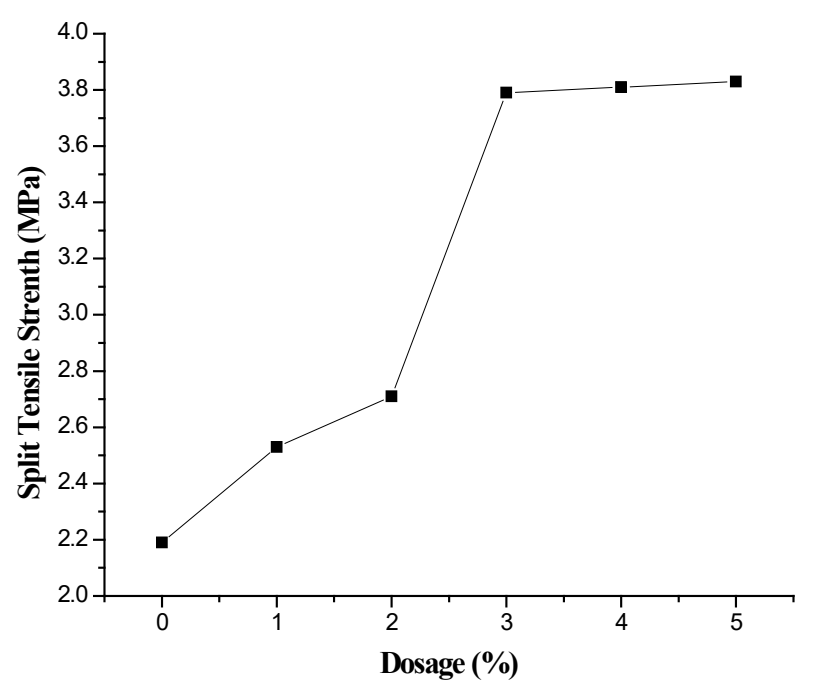

Fig. 6. Split Tensile Strength of Concrete Mixture

The flexural strength of treated and untreated concrete specimens after 28days aging is shown in Fig.7. Regarding the conventional concrete the addition of SMF significantly increases the flexural strength of concrete at age of 28 days by $6 \%$ with dosage of $5 \%$. This strength rise is achieved by the dense structure of the concrete. 


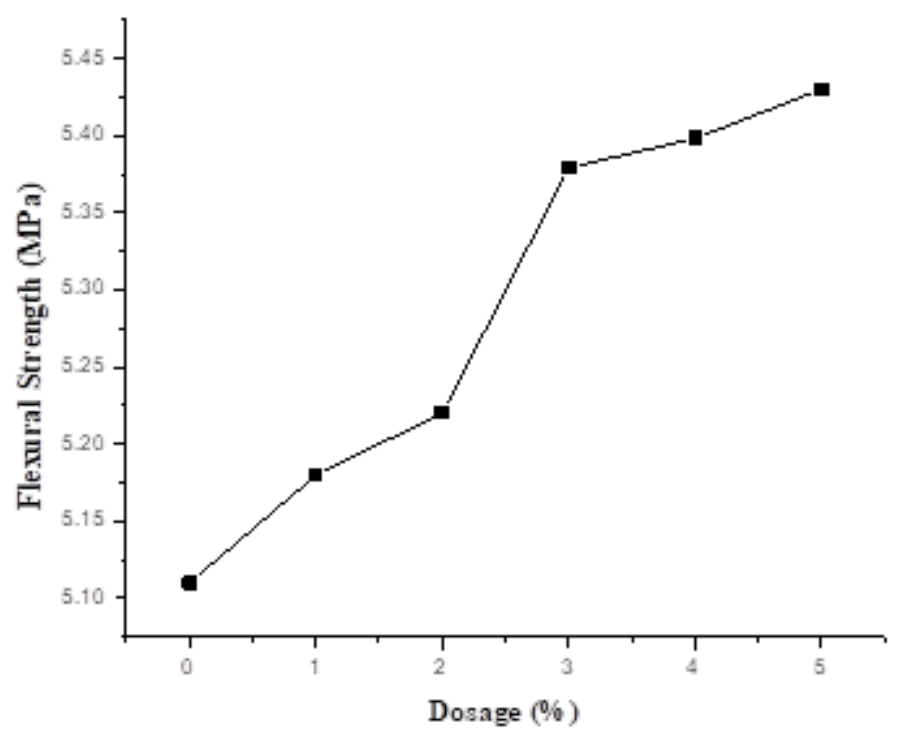

Fig. 7. Flexural strength of concrete mixture

Fig.8. shows the compressive strength result of cementitious system when subjected to acid attack using sulfuric acid with different SMF dosage levels after 90days of immersion in the acid solution. SMF admixed concrete performed well and given higher strength when compared to the conventional concrete. This elevated strength is because of the dense concrete with less water content and less pores. The reduction in pores result in reduction of aggressive solution absorption. So, the acid solution did not have significant damage to the cementitious system. It concludes that the use of SMF improved the resistance against acid environment.

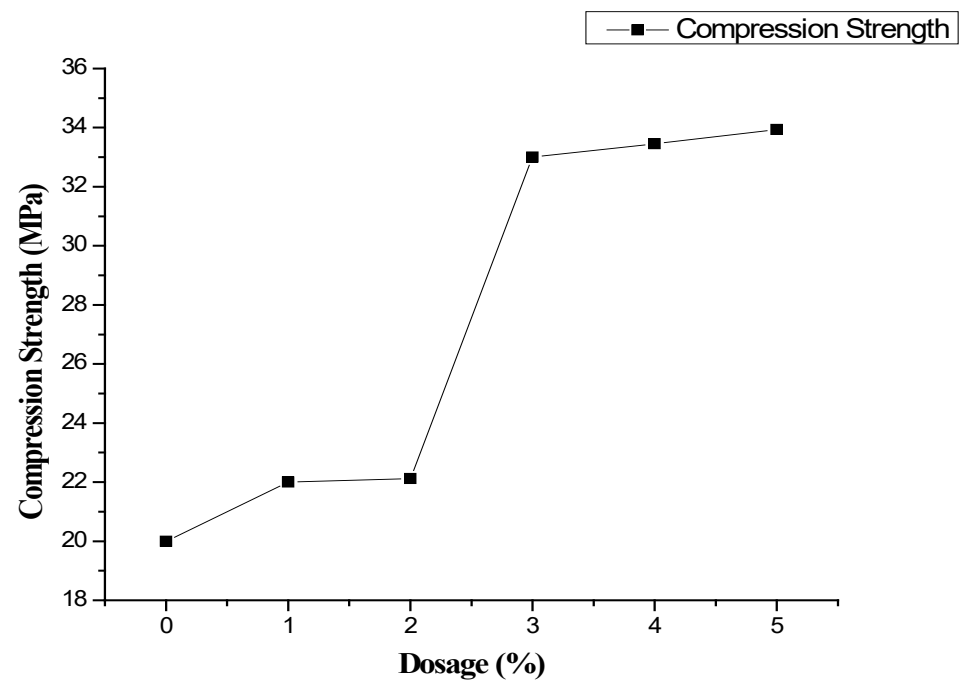

Fig. 8. Acid resistance test

\section{Conclusion}

Industrial available Sulfonated Melamine-Formaldehyde with $20 \%$ solid content used as superplasticizer for the cementitious system. The effects of fresh and harden concrete property with different dosage and ages are investigated. 
- The result infers that the utilization of Sulfonated Melamine-Formaldehyde improves the mechanical strength in compression, tension, and flexural strength test. It also reduces the water content up to 30 percentage when 5 percent increase in SMF.

- The SMF dispersed the cement particle to increase the flowability and affects the hydration processes of cement. Due to this there is a retardation effect in initial setting time test.

- SMF also performed well in acid resistance test. Because the decreased water content and permeable pores improved the durability.

- Higher results were achieved in 5 percentage admix. But dosage of 3 percentage of Sulfonated-Melamine Formaldehyde represent optimum strength rise.

- There is strength rise after 3 percentage dosage, but the result indicates no drastic change. As the economic concern, it is advisable to use 3 percentage admixture in the concrete mixture.

- It concluded that the Sulfonated Melamine-Formaldehyde has the potential to be used as superplasticizer in cementitious system.

\section{References}

[1] MouhcineBen Aicha. (2020). The superplasticizer effect on the rheological and mechanical properties of self-compacting concrete. New Materials in Civil Engineering, Pages 315-331. https://doi.org/10.1016/B978-0-12-818961-0.00008-9

[2] Dhanya Sathyan, , Kalpathy Balakrishnan Anand. (2019). Influence of superplasticizer family on the durability characteristics of fly ash incorporated cement concrete. Construction and Building Materials, 204, 864-874. https://doi.org/10.1016/j.conbuildmat.2019.01.171

[3] Ibragimov, R., \& Fediuk, R. (2019). Improving the early strength of concrete: Effect of mechanochemical activation of the cementitious suspension and using of various superplasticizers. Construction and Building Materials, 226, 839-848. https://doi.org/10.1016/j.conbuildmat.2019.07.313

[4] Chee Ban Cheah, Wee Kang Chow, Chuan Wei Oo, Khang Heng Leow (2020). The influence of type and combination of polycarboxylate ether superplasticizer on the mechanical properties and microstructure of slag-silica fume ternary blended self-consolidating concrete, Journal of Building Engineering 31, 101412. https://doi.org/10.1016/j.jobe.2020.101412 [5] Nowak-Michta, A. (2019). Impact analysis of air-entraining and superplasticizing admixtures on concrete compressive strength. Procedia Structural Integrity, 23, 77-82. https://doi.org/10.1016/j.prostr.2020.01.066

[6] Gupta, N., Gupta, A., Saxena, K. K., Shukla, A., \& Goyal, S. K. (2020). Mechanical and durability properties of geopolymer concrete composite at varying superplasticizer dosage. Materials Today: Proceedings. https://doi.org/10.1016/j.matpr.2020.05.646

[7] Matsuzawa, K., Atarashi, D., Miyauchi, M., \& Sakai, E. (2017). Interactions between fluoride ions and cement paste containing superplasticizer. Cement and Concrete Research, 91, 33-38. https://doi.org/10.1016/j.cemconres.2016.10.006

[8] Nakajima, Y., \& Yamada, K. (2004). The effect of the kind of calcium sulfate in cements on the dispersing ability of poly $\beta$-naphthalene sulfonate condensate superplasticizer. Cement and Concrete Research, 34(5), 839-844. https://doi.org/10.1016/j.cemconres.2003.09.022

[9] Shawqul M.Lahallh, M.Absl-Halabi, Ali M.Ali. (1988) Effect of polymerization conditions of sulfonated-melamine formaldehyde superplasticizers on concrete. Cement and Concrete Research Volume 18, Issue 4, Pages 513-531. https://doi.org/10.1016/0008-8846(88)90044-0 
[10] Arosio, F., Castoldi, L., Ferlazzo, N., \& Forzatti, P. (2007). Influence of solfonated melamine formaldehyde condensate on the quality of building blocks production by extrusion of cement-clay pastes. Applied Clay Science, 35(1-2), 85-93. https://doi.org/10.1016/j.clay.2006.06.004

[11] Ruslan Ibragimov, Roman Fediuk.(2019). Improving the early strength of concrete: Effect of mechanochemical activation of the cementitious suspension and using of various superplasticizers. Construction and Building Materials, 22 839-848. https://doi.org/10.1016/j.conbuildmat.2019.07.313 [12] Abdullah M.Zeyad, AliAlmalki. (2020). Influence of mixing time and superplasticizer dosage on self-consolidating concrete properties. Journal of Materials Research and Technology, V9, 6101-6115. https://doi.org/10.1016/j.jmrt.2020.04.013

[13] Meishan Pei, Zhenfei Wang, Wenwei Li, Jin Zhang, Qiwei Pan, Xiaojuan Qin (2008). The properties of cementitious materials superplasticized with two superplasticizers based on aminosulfonate-phenol-formaldehyde. Construction and Building Materials 22 2382-2385. https://doi.org/10.1016/j.conbuildmat.2007.09.003

[14] Meishan Pei, Dujin Wang, Xianbo Hu, Duanfu Xu. (2000). Synthesis of sodium sulfanilate-phenol-formaldehyde condensate and its application as a superplasticizer in concrete. Cement and Concrete Research 301841 - 1845. https://doi.org/10.1016/S0008-8846(00)00389-6 [15] Alexander N. Chernysheva, Mats Jonssonb, Kerstin Forsberg (2018). Characterization and degradation of a polyaryl ether based superplasticizer for use in concrete barriers in deep geological repositories. Applied Geochemistry95 172-181. https://doi.org/10.1016/j.apgeochem.2018.05.014 [16] A.A.M. Mahmoud, , M.S.H. Shehab, , A.S. El-Dieb. (2010). Concrete mixtures incorporating synthesized sulfonated acetophenone-formaldehyde resin as superplasticizer. Cement \& Concrete Composites 32 392-397. https://doi.org/10.1016/j.cemconcomp.2010.02.005 [17] C Rogin Roberta, Dhanya Sathyana, K B Anand. (2018). Effect of superplasticizers on the rheological properties of fly ash incorporated cement paste. Materials Today: Proceedings 5 23955-23963. https://doi.org/10.1016/j.matpr.2018.10.188

[18] Rixom R, Mailvaganam N. (1999) Chemical admixtures for concrete. 3rd ed. London: E \& FN Spon. https://doi.org/10.4324/9780203017241

[19] Chen SD, Hwang CH, Hsu KC. (1999) The effects of sulphonated phenolic resins on the properties of concrete. Cement Concrete Research 29(2) 255-259. https://doi.org/10.1016/S0008-8846(98)00098-2

[20] Pei M, Yang Y, Zhang X, Zhang J, Dong J. (2004) Synthesis and the effects of water-soluble acetone-formaldehyde resin on the properties of concrete. Cement Concrete Research ;34(8):1417-1420. https://doi.org/10.1016/j.cemconres.2004.01.012

[21] Pei M, Wang D, Hu X, Xu D. (2000). Synthesis of sodium sulfanilate-phenolformaldehyde condensate and its application as a superplasticizer in concrete. Cement Concrete Research 30(11) 1841-1845. https://doi.org/10.1016/S0008-8846(00)00389-6

[22] IS383 - Indian Standard Specification for Coarse and Fine Aggregates from Natural Sources for Concrete

[23] IS 10262 - Indian Standard Concrete Mix Proportioning - Guidelines

[24] IS 516 - Indian Standard Methods of 'Tests for Strength of Concrete

[25] IS 5816 - Indian Standard Splitting tensile strength of concrete 